\section{MS18-05 Structural trend of alkaline carbonates under high pressure}

Pavel N. Gavryushkin ${ }^{1,2}$, Altyna Behtenova ${ }^{1,2}$, Zakhar I. Popov $^{3}$, Konstantin D. Litasov ${ }^{1,2}$, Anton Shatskiy ${ }^{1,2}$

1. V.S. Sobolev Institute of Geology and Mineralogy SB RAS, Novosibirsk 630090, Russia

2. Novosibirsk State University, Novosibirsk 630090, Russia

3. National University of Science and Technology MISIS, Moscow

119049, Russia

email: gavryushkin@igm.nsc.ru

The high-pressure behavior of alkaline carbonates is of practical interest due to the catalytic activity of this compounds in the process of diamond's crystals growth. The fundamental interest is in the construction of the high-pressure structural trend and its comparison with such trends of other $\mathrm{A}_{2} \mathrm{CO} 3$ carbonates and $\mathrm{A}_{2} \mathrm{~B}$ binary compounds. We determine this trend based on complex experimental and theoretical investigation of high-pressure behavior of $\mathrm{Li}_{2} \mathrm{CO}_{3}, \mathrm{Na}_{2} \mathrm{CO}_{3}$ and $\mathrm{K}_{2} \mathrm{CO}_{3}$. Theoretical investigation is based on the evolutionary crystal structure prediction algorithms (USPEX package) and density functional theory (VASP package), pressure range 0-100 $\mathrm{GPa}$. Experiments were performed in the large-volume multi-anvil apparatus installed at the BL04B1 beamline of the Spring- 8 synchrotron radiation facility, pressure range 2-30 GPa.

The sequence of theoretically revealed transitions is presented in Fig.1. All cation arrays of the high-pressure structures are of $\mathrm{AlB}_{2}$-type, ideal or deformed. The simplest high pressure behavior is observed for $\mathrm{Li}_{2} \mathrm{CO}_{3}$, which directly transforms to ideal (hexagonal) $\mathrm{AlB}_{2}^{2}$-type at $8 \mathrm{GPa}$ and stable in this form up to $100 \mathrm{GPa}$. $\mathrm{Na}_{2}^{2} \mathrm{CO}_{3}$ transforms to ideal $\mathrm{AlB}_{3}$-type at $5 \mathrm{GPa}$ and then to deformed monoclinic $(\mathrm{P} 2 / \mathrm{m}) \mathrm{AlB}_{2}$-type at $35 \mathrm{GPa}$. $\mathrm{K}_{2} \mathrm{CO}_{3}$ does not adopt ideal $\mathrm{AlB}_{2}$-type and at $12 \mathrm{GPa}$ transforms to triclinic (P-1), and then to monoclinic phase $(\mathrm{C} 2 / \mathrm{c})$ at $53.5 \mathrm{GPa}$. The last one is the analogue of $\mathrm{P} 2 / \mathrm{m}$-phase of $\mathrm{Na}_{2} \mathrm{CO}_{3}$. The presented results are in good agreement with results of our experiments, according to which ambient $\gamma-\mathrm{Na}_{2} \mathrm{CO}_{3}$ transforms to ideal $\mathrm{AlB}_{2}$-structure at $12 \mathrm{GPa}^{2}$, and $\gamma-\mathrm{K}_{2} \mathrm{CO}_{3}$ transforms to a new phase at $12 \mathrm{GPa}$. The transformation of $\gamma-\mathrm{Li}_{2} \mathrm{CO}_{3}$ into ideal $\mathrm{AlB}_{2}$-structure was observed in the experiments of Grzechnik and co-authors [Grzechnik et al., 2003] above $10 \mathrm{GPa}$.

Thus, according to our results cation arrays of alkaline carbonates transforms from anti- $\mathrm{CaF}_{2}\left(\mathrm{Li}_{2} \mathrm{CO}_{2}\right)$ and from $\mathrm{Ni}_{2}$ In $\left(\mathrm{Na}_{2} \mathrm{CO}_{3}, \mathrm{~K}_{2} \mathrm{CO}_{3}\right)$ types to $\mathrm{AlB}_{2}^{2}$-type. This trend is consistent with that of alkaline sulfides (selenides, tellurides), which under compression goes through the series of phase transitions: anti- $\mathrm{CaF}_{2}---\mathrm{PbCl}_{2}---\mathrm{Ni}_{2} \mathrm{In}---\mathrm{AlB}_{2}$. The correspondence of these two trends is supported by the fact that $\mathrm{PbCl}_{2}$-type structure was revealed in our calculations as the possible phase of $\mathrm{Na}_{2} \mathrm{CO}_{3}$ stable under ambient conditions.

References Grzechnik, A., P. Bouvier, and L. Farina (2003), High-pressure structure of Li2CO3, J. Solid State Chem., 173(1), 13-19.

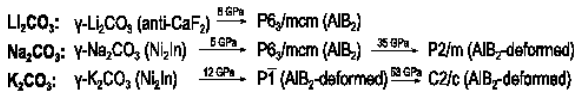

Figure 1. High-pressure phase transitions of $\mathrm{Li}_{2} \mathrm{CO}_{3}, \mathrm{Na}_{2} \mathrm{CO}_{3}$, and $\mathrm{K}_{2} \mathrm{CO}_{3}$.
Keywords: pressure, crystal structure prediction, DFT, experiment, synchrotron radiation 